\title{
Neuroimaging and electroencephalographic (EEG) methods for investigating neural circuits in mental disorders
}

\author{
Métodos de neuroimagem e eletroencefalografia (EEG) para investigação de \\ circuitos neurais em transtornos mentais
}

\author{
Mario Minor Murakami Junior ${ }^{1}$, Marcelo Q. Hoexter ${ }^{1}$, Elizabeth Shephard ${ }^{1,2}$
}

Murakami Junior MM, Hoexter MQ, Shephard E. Neuroimaging and electroencephalographic (EEG) methods for investigating neural circuits in mental disorders / Métodos de neuroimagem e eletroencefalografia (EEG) para investigação de circuitos neurais em transtornos mentais. Rev Med (São Paulo). 2019 July-Aug;98(4):259-66.

\begin{abstract}
It is increasingly recognised that dysfunction in neural circuits plays a key role in the neurobiological basis of mental disorders. The efficacy of pharmacological and behavioural treatments for mental disorders could therefore be improved by targeting dysfunctions in neurocircuits. However, to achieve this, a better understanding of the specific alterations in neural circuits involved in different mental disorders is required. Such understanding can be acquired by using advanced neuroscience methods to examine the pathways and function of neurocircuits in both typically developing individuals and in those with mental disorders. This article provides an overview of currently available neuroscience methods of investigating neural circuits, including advantages and limitations of different techniques, and highlights the importance of using multi-modal imaging in future research.
\end{abstract}

Keywords: Magnetic resonance imaging; Diffusion tensor imaging; Electroencephalography; Mental disorders; Multimodal imaging.
RESUMO: É cada vez mais reconhecido que a disfunção nos circuitos neurais desempenha um papel fundamental na base neurobiológica dos transtornos mentais. A eficácia dos tratamentos farmacológicos e comportamentais para os transtornos mentais pode, portanto, ser melhorada por direcionar as disfunções nos neurocircuitos. No entanto, para isso, é necessário um melhor entendimento das alterações específicas nos circuitos neurais envolvidos em diferentes transtornos mentais. Tal entendimento pode ser adquirido usando-se métodos avançados de neurociência para examinar as vias e a função dos neurocircuitos em indivíduos com desenvolvimento típico e naqueles com transtornos mentais. Este artigo fornece uma visão geral dos métodos da neurociência atualmente disponíveis na investigação de circuitos neurais, incluindo vantagens e limitações de diferentes técnicas, e destaca a importância do uso de imagens multimodais em pesquisas futuras.

Descritores: Imagem por ressonância magnética; Imagem de tensor de difusão; Eletroencefalografia; Transtornos mentais; Imagem multimodal.

1. Institute of Psychiatry, University of São Paulo, Brazil. ORCID: Murakami Junior MM - https://orcid.org/0000-0003-4232-1550; Hoexter MQ https://orcid.org/0000-0002-9302-4380. Email: mario.minor@fm.usp.br; mqhoexter@gmail.com.

2. Institute of Psychiatry, Psychology \& Neuroscience (IoPPN), King’s College London, UK. Email: lizzieshephard@gmail.com.

Correspondence: Rua Capote Valente, 640. Apart. 172. Pinheiros. 05409-002 - São Paulo, SP, Brazil. 


\section{INTRODUCTION}

T is increasingly recognised that dysfunction neurobiological basis of mental disorders, including obsessive-compulsive disorder (OCD), depression, attention-deficit/hyperactivity disorder (ADHD), autism spectrum disorder (ASD) and schizophrenia ${ }^{1-9}$. One approach to improving the efficacy of treatments for mental disorders is therefore to ensure that pharmacological and behavioural therapies are targeted at remedying dysfunctions within the neurocircuit(s) involved in the disorder. However, the exact neurocircuits and specific dysfunctions within those circuits involved in different mental disorders are not yet fully understood. To address this issue, advanced neuroscience methods should be used to understand the anatomical projections and function of neurocircuits in typically developing individuals, and then to identify alterations in those circuits in individuals with different mental disorders. A number of different neuroscience techniques are available to probe the integrity and function of neurocircuits, including magnetic resonance imaging (MRI), functional MRI (fMRI), electroencephalography (EEG), magnetoencephalography (MEG) and functional near infra-red spectroscopy (fNIRS). This article will provide an overview of three of these methods, diffusion tensor imaging (DTI), resting state fMRI (rs-fMRI) and EEG, illustrating how each method can be used to investigate neurocircuits. Advantages and limitations of each technique and future directions for investigating neurocircuit dysfunctions in mental disorders will be discussed.

\section{DISCUSSION}

\section{DTI}

DTI is a non-invasive type of magnetic resonance imaging that uses a bipolar magnetic field gradient pulse to encode molecular diffusion of water ${ }^{10}$. Using different measures of diffusion in multiple directions, it is possible to employ tensor decomposition and extract information that is related to the direction of water diffusion and amount of diffusion ${ }^{11}$. DTI measures the parallel and perpendicular diffusivities of a tensor in a fiber ${ }^{11}$, from which it is possible to calculate the fractional anisotropy (FA) and the mean diffusivity (MD) of a white matter tract ${ }^{12}$. These measures can provide indexes of white matter fiber density and integrity, orientation, and myelination. Therefore, DTI yields a quantitative analysis of anatomical connectivity in the white matter fibers throughout the brain in vivo. Using a deterministic or probabilistic algorithm, it is also possible to extract the fiber tractography image ${ }^{13}$ to determine intervoxel connectivity based on anisotropic diffusion of water and visualize white matter tracts in $3 \mathrm{D}^{14}$. Tractography can show the microstructure of white matter tracts, improving the analysis of the structure of white matter and allowing the investigation of neuroanatomical projections, i.e. tractography facilitates the investigation of structural connectivity (Figure 1).

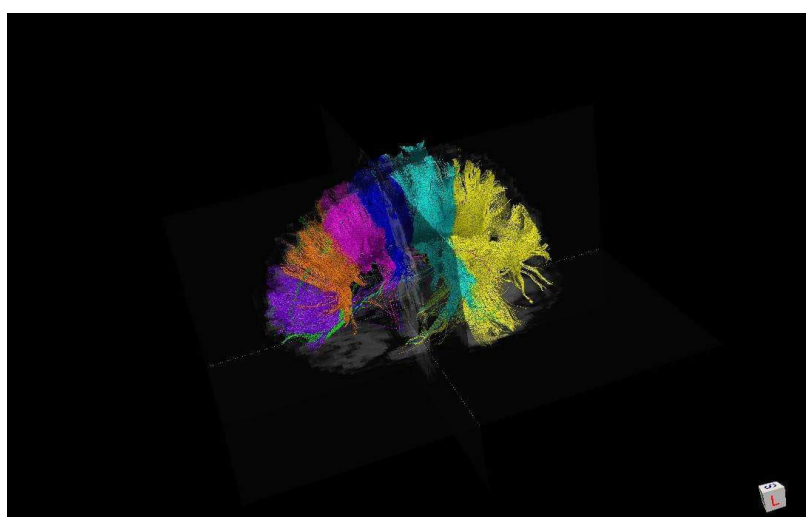

Figure 1: Example of tractography image of the corpus callosum. Tractography is a tool that allows the researcher and the clinician to visualize the connectivity and the white matter trajectory in vivo and noninvasively of patients. Image from Elizabeth Shephard (King's College London)

DTI has several potential applications for the understanding of structural brain connectivity in both typically developing individuals and in those with mental disorders. For example, in typically developing individuals, DTI revealed that the ventral part of the anterior limb of the internal capsule (ALIC) carries fibers of the ventral medial prefrontal and orbitofrontal cortices, whereas the dorsal components carry fibers of ventral lateral prefrontal cortex (ventrolateral ALIC), dorsal lateral prefrontal cortex (dorsolateral ALIC), dorsal anterior cingulate cortex (ventromedial ALIC), and medial prefrontal cortex (dorsomedial ALIC) ${ }^{15}$. Interestingly, Makris and colleagues have shown that these projections have a high interindividual variability in their topography ${ }^{16}$.

In psychiatric disorders, studies using DTI showed that frontal-temporal connectivity is disrupted in schizophrenia ${ }^{17}$. Specifically, the uncinate fasciculus (UF), a white matter tract connecting temporal and frontal brain regions that have a role in decision-making, episodic memory and emotions, was abnormal in patients with schizophrenia ${ }^{18}$. Further, other research has indicated that the cingulum bundle, a tract that is related to spatial orientation, memory, emotions, and attention, is also abnormal in patients with schizophrenia ${ }^{19}$. DTI has revealed structural connectivity alterations in other disorders as well. For instance, a recent meta-analysis 
reported reduced organization of limbic connectivity and microstructural disorganization of the anterior limb of the internal capsule, temporal-parietal white matter and left posterior cingulum in patients with bipolar disorder (BD) ${ }^{20}$. These microstructures were related to altered emotional processing and dysfunctional limbic connectivity in $\mathrm{BD}^{21}$. Another cluster of dysfunctional tracts in $\mathrm{BD}$ is the integration of the inferior occipital fasciculus, the inferior longitudinal fasciculus, the superior longitudinal fasciculus and the posterior thalamic radiations that are related to the parahippocampal gyrus ${ }^{22,23}$. In addition, other studies have revealed lower FA in several brain regions, including the anterior cingulate gyrus, supramarginal gyrus, cingulate gyrus and lingual gyri, in OCD patients compared with controls $^{24,25}$.

DTI is also a technique that can help in the improvement or development of neuromodulatory targeted treatments ${ }^{26}$ such as transcranial magnetic stimulation, transcranial direct current stimulation, deep brain stimulation, and ablative neurosurgeries because it can map specific brain circuits to be modulated by these procedures ${ }^{16}$. Riva-Posse et al. ${ }^{27}$, for example, have used an individualized, patient-specific, deterministic tractography approach for individually targeting subcallosal cingulate deep brain stimulation surgery in patients with depression.

In sum, the major strength of diffusion techniques is the ability to indirectly measure anatomic structure in vivo, allowing the investigation of white matter integrity and the construction of structural connectivity maps. However, this method has limitations including its level of resolution and its inability to determine complex fiber organization, such as in regions that have crossing fibers, which has led to the failure to detect already known pathways $^{28}$. Yet, DTI and tractography are powerful imaging techniques to assess microstructural white matter tracts in psychiatric disorders.

\section{Rs-fMRI}

Rs-fMRI is a tool to investigate brain regions that show correlated fluctuations in activity and is a suitable technique to uncover functional activation within the brain. Rs-fMRI provides information about functional connectivity ${ }^{2,29-35}$, i.e. this technique measures temporal correlations in blood oxygen level dependent (BOLD) low-frequency fluctuations between distinct remote brain areas by assessing the coherence of spontaneous neural fluctuations over time. This concept is based on the observation that distant direct or indirect interconnected brain regions often show strong correlations in their activity levels (Figure 2).
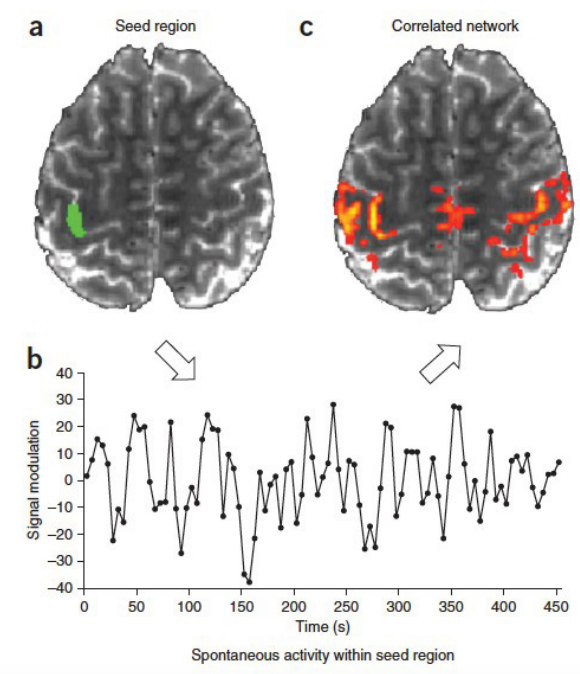

Figure 2: The basic strategy of intrinsic functional connectivity MRI (fcMRI). The basis of fcMRI is that spontaneous activity fluctuations measured at rest are correlated between regions. Inferences can be made about the organization of the brain by measuring correlations among brain regions. (a) An example seed region in the motor cortex (green). Activity in this region is measured indirectly through the blood oxygenation leveldependent MRI signal. (b) The time course of intrinsic activity fluctuations for the seed region for a period of $7 \mathrm{~min}$. The general strategy of functional connectivity is to determine the network of brain regions that show correlated activity fluctuations over time with the seed region. (c) In this example, many cortical regions in the motor system are correlated with the seed region. Image from K. Van Dijk (Massachusetts General Hospital)

Thus, rs-fMRI is particularly useful for providing a sensitive measurement of functional connectivity in largescale brain networks in humans. There are several different ways to assess resting state functional connectivity. Two of them are: 1) a seed-based approach that calculates the correlation between extracted regions of interest and 2) an ICA (Independent Component Analyses)-based approach that uses all brain voxels' activity to separate brain functional networks that are correlated with spontaneous component of BOLD signa ${ }^{36}$. Anatomical models have suggested that information in the brain is transferred along a ventral to dorsal gradient through striatum circuits that go from emotional/motivational (prediction error; feedbackrelated reinforcement; reward anticipation; incentive salience) brain regions to decision making/executive control (e.g. verbal and spatial working memory; response inhibition; task switching; reasoning; planning) regions and then to motor control regions ${ }^{37}$. As in anatomical models, Di Martino and colleagues performed a rs-fMRI study to map the functional connectivity of the striatum circuitry in typically developing individuals ${ }^{38}$. They subdivided striatal subregions by defining 6 seed regions in dorsal caudate (DC), superior ventral caudate (VCs), inferior ventral caudate/nucleus accumbens (VCi), dorsal 
rostral putamen (DRP), dorsal caudal putamen (DCP), and ventral rostral putamen (VRP) and hypothesized that differential patterns of connectivity would be noted across these 6 striatal subregions. According to their hypotheses, among the caudate subregions, the inferior ventral striatal region (VSi) exhibited greater connectivity with limbic and medial orbitofrontal regions whereas the VSs seed predicted patterns of activity in more superior and lateral portions of the orbitofrontal cortex. Specifically, VSi predicted activation within regions implicated in emotional processing such as parahippocampal gyrus, and posterior cingulate cortex, whereas the VSs seed predicted activity in regions associated with executive function, decision-making, and motor planning such as dorsolateral prefrontal cortex, inferior frontal gyrus, and rostral anterior cingulate. On the other hand, dorsal caudate showed greater connectivity with the dorsolateral prefrontal and parietal cortices, areas that are involved in cognitive control. The caudal putamen seeds were significantly correlated with primary and supplementary motor cortices, whereas the rostral putamen seed revealed patterns of connectivity with frontal regions implicated in executive function control. Thus, these findings suggest dorsal/ventral distinction in striatum connectivity, which are consistent with structural anatomical models postulating an affective/ cognitive/ motor division between ventral and dorsal portions of the striatum $^{37}$.

Striatum functional connectivity has also been studied in several psychiatric conditions associated with emotional and executive/motivational deficits, including schizophrenia, substance use disorders, OCD, major depressive disorder, and ADHD. Some examples: in patients with schizophrenia, the functional connectivity between the salience network covering prefrontal-limbic cortices to mediodorsal thalamus and ventral parts of striatum was hypoconnected. Interestingly, this pattern of hypoconnectivity was correlated with impaired cognition ${ }^{39}$. Individuals with cocaine dependence demonstrated reduced functional connectivity between ventral portions of the ventral striatum with ventromedial prefrontal cortex (vmPFC) and increased dorsal-anterior ventral striatum functional connectivity with visual cortex compared to controls ${ }^{40}$. In a study performed in OCD, patients presented increased functional connectivity between ventral corticostriatal circuits compared to controls, implicating the orbitofrontal cortex ${ }^{2}$. Using an ICA approach, Leaver and colleagues have shown that patients with depression exhibited hyperconnectivity between ventral striatum (VS) and the ventral default-mode network (vDMN), while simultaneously demonstrating hypoconnectivity with the anterior DMN $(\mathrm{aDMN})^{41}$. In ADHD patients, inattention and hyperactivity/impulsivity symptom were correlated with increases in functional connectivity in the networks of posterior putamen and ventral caudate whereas increased connectivity of posterior putamen with motor cortex and cerebellum was associated with decreased motor performance ${ }^{42}$.

In sum, rs-fMRI is a tool that allows mapping functional brain organization in both typically developing individuals and in those with mental disorders. Nevertheless, it should be kept in mind that this technique does not provide direct information for anatomical connectivity and is subject to several types of technical artifacts that confound its interpretation, such as head motion and physiological artifacts related to cardiac and respiratory rhythms.

\section{EEG}

EEG measures electrophysiological (electrical) neural activity from electrodes placed on the scalp. The electrophysiological signal (Figure 3) is a summation of electrical fields generated by post-synaptic potentials in cortical neurons; these electrical field are conducted through the layers of brain tissue and the skull to the scalp, where they are detected as voltage changes in the electrical potential of the $\operatorname{skin}^{43,44}$. The electrophysiological signal must be generated by synchronously-firing post-synaptic potentials in large $(10,000-50,000)$ populations of neurons to be detectable at the scalp; signals generated by smaller populations of neurons will diminish during the conduction process and will dissipate before reaching the scalp $^{43,45}$. There are some brain regions from which it is impossible to measure electrophysiological activity with EEG, specifically the deep brain structures (amygdala, hippocampus, insula) and the inner surfaces of cortical fissures, because in these regions the electrical fields generated by neurons are too distant for the signals to reach the scalp or cancel each other out due to their opposing alignment ${ }^{43-45}$. Another important limitation of EEG is volume conduction: during the propagation of the electrophysiological signal from cortical neurons to the scalp, the signal becomes smeared outwards as well as upwards. Consequently, it is not possible to determine which specific brain regions generated a signal recorded on the scalp, and the spatial resolution of EEG is therefore limited. Still, EEG is a powerful tool for investigating brain function and, unlike fMRI, measures neuronal activity directly as opposed to blood flow to different brain regions. Furthermore, EEG has an exceptionally high temporal resolution and measures neural activity in the millisecond time-range, rather than in the second time-range of fMRI. 


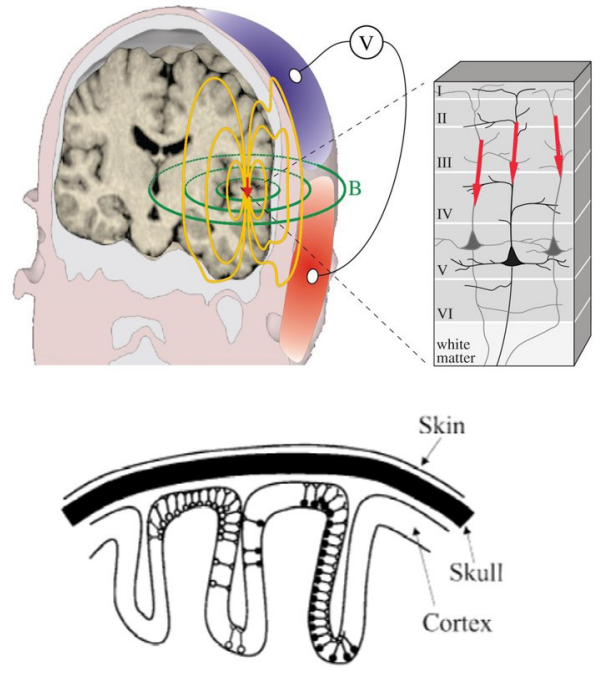

Figure 3: Top panels: The electrophysiological signal. Electrical fields (indicated in yellow) are generated by post-synaptic potentials (red arrows) and are conducted through the layers of brain tissue and skull to reach the scalp, where they are detected as voltage changes (blue/red areas) on the skin by electrodes. Bottom panel: To be detectable on the scalp, electrical fields must be generated by large $(10,000-50,000)$ populations of geometrically aligned neurons, and not from neurons inside fissures (because their electrical fields will cancel each other out). Figure adapted from Hari and Parkkonen ${ }^{45}$

There are several methods of processing and analysing EEG data, which are informative about different aspects of brain function. The simplest and most widely used is referred to as event-related potentials (ERPs). An ERP is the averaged electrophysiological activity (averaged across experimental task trials) that occurs in response to a specific event (e.g. a stimulus or motor response). The ERP waveform consists of positive and negative deflections which are referred to as ERP components; these components are defined in terms of their amplitude (the magnitude of the positive or negative deflection measured in microvolts, $\mu \mathrm{v}$ ), latency (the time in milliseconds, ms, for the deflection to reach its maximal positive or negative amplitude) and topography (the distribution of the electrical potential across the scalp) (Figure 4). Different ERP components reflect different neurocognitive processes (see $\mathrm{Luck}^{46}$, Nelson and McLeery ${ }^{47}$ for reviews of common ERP components $)^{46,47}$, which can be used to probe the function and dysfunction of different neural circuits in typical developing individuals and in those with mental disorders. For example, the N170 component (a negative component that peaks $\sim 170 \mathrm{~ms}$ post-stimulus) indexes neurocognitive processes specialised for face perception in right-hemisphere brain circuits ${ }^{48}$. The N170 changes in amplitude and latency across typical child development, indicating that neurocircuitry responsible for processing social stimuli such as faces matures slowly from infancy through to adolescence and early adulthood ${ }^{49}$. The N170 has been extensively studied in ASD and shows robust atypicalities in individuals with the disorder and in unaffected first-degree relatives, suggesting that impaired face processing is a key deficit in ASD and may act as an endophenotypic trait that indexes genetic risk for the disorder ${ }^{50,51}$. Interestingly, the N170 shows similar atypicalities in individuals with schizophrenia ${ }^{52,53}$, which adds to the growing body of evidence that there is a high degree of overlap in the neurocircuits affected in ASD and schizophrenia ${ }^{54}$. Another ERP component that has been particularly valuable in understanding neurocircuit alterations in mental disorders is the error-related negativity (ERN) which indexes behavioural monitoring and reinforcement learning functions of the anterior cingulate cortex and is atypically increased in $\mathrm{OCD}^{55}$ and atypically decreased in $\mathrm{ADHD}^{56}$.

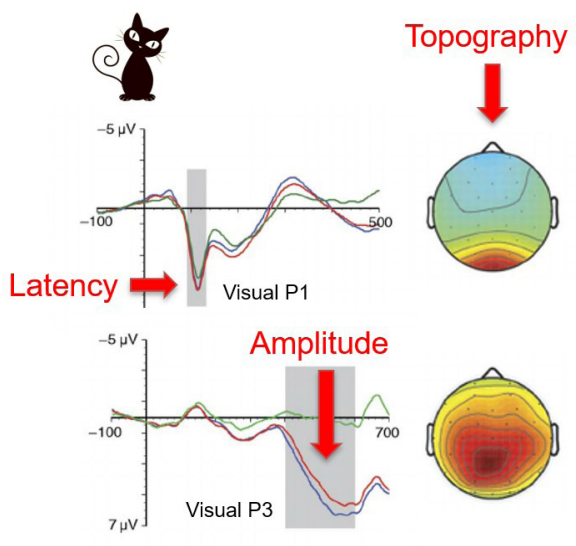

Figure 4: Event-related potentials (ERPs). An ERP is the average electrophysiological activity that occurs in response to an event (e.g. a cat stimulus). The ERP waveform consists of positive and negative peaks, termed ERP components. These components (e.g. P1, P3) are characterised by their amplitude (magnitude of positivity and negativity), latency (time to reach maximal amplitude) and topography (the distribution of the electrical potential on the scalp)

A second method of analysing EEG data is to decompose the time-domain electrophysiological signal into the frequency domain and examine oscillatory neuronal activity in different frequencies. Oscillatory activity is particularly important because it is believed to be the mechanism by which both local and large-scale populations of neurons communicate with one another and the basis for functional connectivity ${ }^{57}$. Oscillatory activity in different frequencies is associated with different neurocognitive functions. Low-frequency theta $(4-8 \mathrm{~Hz})$ activity is associated with self-regulatory executive functions ${ }^{58,59}$, mid-frequency alpha $(8-12 \mathrm{~Hz})$ is associated 
with attention and cortical inhibition ${ }^{60}$, and high-frequency gamma $(>30 \mathrm{~Hz})$ is associated with perceptual integration and learning ${ }^{44,61}$. Oscillatory activity can be quantified by its magnitude (power, amplitude ${ }^{2}$ ) at different scalp regions and by its functional connectivity, i.e. the extent to which oscillatory signals are synchronised (have the same timing) across different scalp regions (Figure 5; for in-depth discussion of oscillatory activity measures see Cohen ${ }^{62}$, Roach and Mathalon ${ }^{63}$ ). Both power and synchrony measures have revealed important insights into the neural mechanisms affected in mental disorders. For example, reduced oscillatory power and connectivity in the alpha frequency is a robust finding in children and adults with ASD and is present across resting and cognitive task ${ }^{64-66}$. Since alpha oscillations index cortical inhibition and are mediated by inhibitory GABA-ergic neurotransmission ${ }^{60}$, the reduced alpha in ASD indicates that impaired or inefficient inhibitory neuronal circuitry is a key mechanism involved in this disorder; indeed, recent research indicates that GABA-modulating drugs may be effective in reducing ASD symptoms and restoring functional neural connectivity ${ }^{39}$.

\section{CONCLUSIONS}

Dysfunctions in neurocircuits play an important role in the neurobiology of mental disorders and now we have better tools for exploring human brain connectivity in more detail. Herein, we have discussed three main

\section{REFERENCES}

1. Castellanos FX, Proal E. Large-scale brain systems in ADHD: beyond the prefrontal-striatal model. Trends Cogn Sci. 2012;16(1):17-26. doi: 10.1016/j.tics.2011.11.007.

2. Harrison BJ, Soriano-Mas C, Pujol J, Ortiz H, LopezSola M, Hernandez-Ribas R, et al. Altered corticostriatal functional connectivity in obsessive-compulsive disorder. Arch Gen Psychiatry. 2009;66(11):1189-200. doi: 10.1001/ archgenpsychiatry.2009.152.

3. Johnson MH. Autism as an adaptive common variant pathway for human brain development. Dev Cogn Neurosci. 2017;25:5-11. doi: 10.1016/j.den.2017.02.004.

4. Krystal JH, Anticevic A, Yang GJ, Dragoi G, Driesen NR, Wang XJ, et al. Impaired Tuning of Neural Ensembles and the Pathophysiology of Schizophrenia: A Translational and Computational Neuroscience Perspective. Biol Psychiatry. 2017;81(10):874-85. doi: 10.1016/j.biopsych.2017.01.004.

5. Lisman JE, Coyle JT, Green RW, Javitt DC, Benes FM, Heckers S, et al. Circuit-based framework for understanding neurotransmitter and risk gene interactions in schizophrenia. Trends Neurosci. 2008;31(5):234-42. doi: 10.1016/j. tins.2008.02.005.

6. Mueller A, Hong DS, Shepard S, Moore T. Linking ADHD to the Neural Circuitry of Attention. Trends Cogn Sci. 2017;21(6):474-88.10.1016/j.tics.2017.03.009

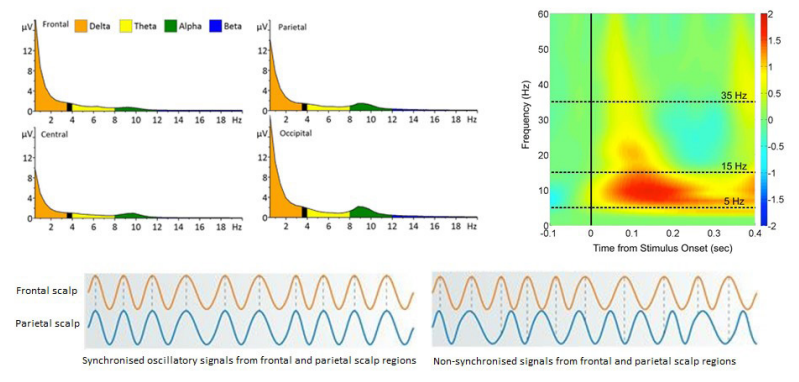

Figure 5: Oscillatory power measures. Power (amplitude ${ }^{2}$ ) of oscillatory activity in different frequencies (delta, theta, alpha, beta, gamma) can be measured as the average across a certain time-period (top left) or as time-varying fluctuations following an event (top right) at different scalp regions. Oscillatory synchrony (bottom) reflects the extent to which oscillatory activity from different scalp regions occurs with the same timing

techniques that allow the investigation and mapping of the in vivo human brain in a non-invasive way: DTI, rs-fMRI and EEG. As mentioned, all these methods measure different things and have their own strengths and weaknesses, but they are complementary to each other. Thus, we acknowledge the importance of using multi-modal imaging in future research in order to generate more precise and complex information about the structural and functional connectivity of the human brain both in typically developing individuals and in those with mental disorders.

7. Radua J, Grau M, van den Heuvel OA, Thiebaut de Schotten M, Stein DJ, Canales-Rodriguez EJ, et al. Multimodal voxel-based meta-analysis of white matter abnormalities in obsessive-compulsive disorder. Neuropsychopharmacology. 2014;39(7):1547-57. doi: 10.1038/npp.2014.5.

8. Brakowski J, Spinelli S, Dorig N, Bosch OG, Manoliu A, Holtforth MG, et al. Resting state brain network function in major depression - Depression symptomatology, antidepressant treatment effects, future research. J Psychiatr Res. 2017;92:147-59. doi: 10.1016/j.jpsychires.2017.04.007.

9. Wolff JJ, Swanson MR, Elison JT, Gerig G, Pruett JR, Jr., Styner MA, et al. Neural circuitry at age 6 months associated with later repetitive behavior and sensory responsiveness in autism. Mol Autism. 2017;8:8. doi: 10.1186/s13229-0170126-z.

10. Le Bihan D, Mangin JF, Poupon C, Clark CA, Pappata S, Molko N, et al. Diffusion tensor imaging: concepts and applications. J Magn Reson Imaging. 2001;13(4):534-46. https://doi.org/10.1002/jmri.1076.

11. AssafY, Pasternak O. Diffusion tensor imaging (DTI)-based white matter mapping in brain research: a review. J Mol Neurosci. 2008;34(1):51-61. doi: 10.1007/s12031-0070029-0.

12. Siasios I, Kapsalaki EZ, Fountas KN, Fotiadou A, 
Dorsch A, Vakharia K, et al. The role of diffusion tensor imaging and fractional anisotropy in the evaluation of patients with idiopathic normal pressure hydrocephalus: a literature review. Neurosurg Focus. 2016;41(3):E12. doi: 10.3171/2016.6.FOCUS16192.

13. Lawes IN, Barrick TR, Murugam V, Spierings N, Evans DR, Song M, et al. Atlas-based segmentation of white matter tracts of the human brain using diffusion tensor tractography and comparison with classical dissection. Neuroimage. 2008;39(1):62-79. doi: 10.1016/j.neuroimage.2007.06.041.

14. Mukherjee P, Berman JI, Chung SW, Hess CP, Henry RG. Diffusion tensor MR imaging and fiber tractography: theoretic underpinnings. AJNR Am J Neuroradiol. 2008;29(4):632-41. doi: 10.3174/ajnr.A1051.

15. Safadi Z, Grisot G, Jbabdi S, Behrens TE, Heilbronner SR, McLaughlin NCR, et al. Functional Segmentation of the Anterior Limb of the Internal Capsule: Linking White Matter Abnormalities to Specific Connections. J Neurosci. 2018;38(8):2106-17. doi: 10.1523/ JNEUROSCI.2335-17.2017.

16. Makris N, Rathi Y, Mouradian P, Bonmassar G, Papadimitriou $\mathrm{G}$, Ing WI, et al. Variability and anatomical specificity of the orbitofrontothalamic fibers of passage in the ventral capsule/ ventral striatum (VC/VS): precision care for patient-specific tractography-guided targeting of deep brain stimulation (DBS) in obsessive compulsive disorder (OCD). Brain Imaging Behav. 2016;10(4):1054-67. doi: 10.1007/s11682015-9462-9.

17. Kubicki M, Westin CF, McCarley RW, Shenton ME. The application of DTI to investigate white matter abnormalities in schizophrenia. Ann N Y Acad Sci. 2005;1064:134-48. doi: 10.1196/annals. 1340.024

18. Kubicki M, Westin CF, Maier SE, Frumin M, Nestor PG, Salisbury DF, et al. Uncinate fasciculus findings in schizophrenia: a magnetic resonance diffusion tensor imaging study. Am J Psychiatry. 2002;159(5):813-20. doi: 10.1176/appi.ajp.159.5.813.

19. Sun Z, Wang F, Cui L, Breeze J, Du X, Wang X, et al. Abnormal anterior cingulum in patients with schizophrenia: a diffusion tensor imaging study. Neuroreport. 2003;14(14):1833-6. doi: 10.1097/01.wnr.0000094529.75712.48.

20. Nortje G, Stein DJ, Radua J, Mataix-Cols D, Horn N. Systematic review and voxel-based meta-analysis of diffusion tensor imaging studies in bipolar disorder. J Affect Disord. 2013;150(2):192-200. doi: 10.1016/j.jad.2013.05.034.

21. Wessa M, Kanske P, Linke J. Bipolar disorder: a neural network perspective on a disorder of emotion and motivation. Restor Neurol Neurosci. 2014;32(1):51-62. doi: 10.3233/ RNN-139007.

22. Vederine FE, Wessa M, Leboyer M, Houenou J. A meta-analysis of whole-brain diffusion tensor imaging studies in bipolar disorder. Prog Neuropsychopharmacol Biol Psychiatry. 2011;35(8):1820-6. doi: 10.1016/j. pnpbp.2011.05.009.

23. O'Donoghue S, Holleran L, Cannon DM, McDonald C. Anatomical dysconnectivity in bipolar disorder compared with schizophrenia: A selective review of structural network analyses using diffusion MRI. J Affect Disord. 2017;209:21728. doi: 10.1016/j.jad.2016.11.015.

24. Szeszko PR, Ardekani BA, Ashtari M, Malhotra AK, Robinson DG, Bilder RM, et al. White matter abnormalities in obsessive-compulsive disorder: a diffusion tensor imaging study. Arch Gen Psychiatry. 2005;62(7):782-90. doi: 10.1001/archpsyc.62.7.782.

25. Kwon JS, Kim JJ, Lee DW, Lee JS, Lee DS, Kim MS, et al. Neural correlates of clinical symptoms and cognitive dysfunctions in obsessive-compulsive disorder. Psychiatry Res. 2003;122(1):37-47. https://doi.org/10.1016/S09254927(02)00104-X.

26. Pasternak O, Kelly S, Sydnor VJ, Shenton ME. Advances in microstructural diffusion neuroimaging for psychiatric disorders. Neuroimage. 2018;182:259-82. doi: 10.1016/j. neuroimage.2018.04.051.

27. Riva-Posse P, Choi KS, Holtzheimer PE, Crowell AL, Garlow SJ, Rajendra JK, et al. A connectomic approach for subcallosal cingulate deep brain stimulation surgery: prospective targeting in treatment-resistant depression. Mol Psychiatry. 2018;23(4):843-9. doi: 10.1038/mp.2017.59.

28. Jones DK. Tractography gone wild: probabilistic fibre tracking using the wild bootstrap with diffusion tensor MRI. IEEE Trans Med Imaging. 2008;27(9):1268-74. doi: 10.1109/ TMI.2008.922191.

29. Jang JH, Kim JH, Jung WH, Choi JS, Jung MH, Lee JM, et al. Functional connectivity in fronto-subcortical circuitry during the resting state in obsessive-compulsive disorder. Neurosci Lett. 2010;474(3):158-62. doi: 10.1016/j.neulet.2010.03.031.

30. Stern ER, Fitzgerald KD, Welsh RC, Abelson JL, Taylor SF. Resting-state functional connectivity between frontoparietal and default mode networks in obsessive-compulsive disorder. PloS One. 2012;7(5):e36356. doi: 10.1371/journal. pone. 0036356 .

31. Sakai Y, Narumoto J, Nishida S, Nakamae T, Yamada K, Nishimura T, et al. Corticostriatal functional connectivity in non-medicated patients with obsessive-compulsive disorder. European psychiatry : the journal of the Association of European Psychiatrists. 2011;26(7):463-9. doi: 10.1016/j. eurpsy.2010.09.005.

32. Beucke JC, Sepulcre J, Talukdar T, Linnman C, Zschenderlein $\mathrm{K}$, Endrass T, et al. Abnormally high degree connectivity of the orbitofrontal cortex in obsessive-compulsive disorder. JAMA psychiatry. 2013;70(6):619-29.10.1001/ jamapsychiatry.2013.173.

33. Fitzgerald KD, Welsh RC, Stern ER, Angstadt M, Hanna GL, Abelson JL, et al. Developmental alterations of frontal-striatal-thalamic connectivity in obsessivecompulsive disorder. J Am Acad Child Adolesc Psychiatry. 2011;50(9):938-48 e3. doi: 10.1016/j.jaac.2011.06.011.

34. Fitzgerald KD, Stern ER, Angstadt M, Nicholson-Muth KC, Maynor MR, Welsh RC, et al. Altered function and connectivity of the medial frontal cortex in pediatric obsessivecompulsive disorder. Biol Psychiatry. 2010;68(11):1039-47. doi: 10.1016/j.biopsych.2010.08.018.

35. Gruner P, Vo A, Argyelan M, Ikuta T, Degnan AJ, John M, et al. Independent component analysis of resting state activity in pediatric obsessive-compulsive disorder. Hum Brain Mapp. 2014;35(10):5306-15. doi: 10.1002/hbm.22551.

36. Fox MD, Raichle ME. Spontaneous fluctuations in brain activity observed with functional magnetic resonance imaging. Nat Rev Neurosci. 2007;8(9):700-11. doi: 10.1038/ nrn2201.

37. Haber SN. The primate basal ganglia: parallel and integrative networks. J Chem Neuroanat. 2003;26(4):317-30. https://doi org/10.1016/j.jchemneu.2003.10.003.

38. Di Martino A, Scheres A, Margulies DS, Kelly AM, 
Uddin LQ, Shehzad Z, et al. Functional connectivity of human striatum: a resting state FMRI study. Cereb Cortex. 2008;18(12):2735-47. doi: 10.1093/cercor/bhn041.

39. Ajram LA, Horder J, Mendez MA, Galanopoulos A, Brennan LP, Wichers RH, et al. Shifting brain inhibitory balance and connectivity of the prefrontal cortex of adults with autism spectrum disorder. Transl Psychiatry. 2017;7(5):e1137. doi: 10.1038/tp.2017.104.

40. Zhang S, Li CR. Ventral striatal dysfunction in cocaine dependence - difference mapping for subregional resting state functional connectivity. Transl Psychiatry. 2018;8(1):119. doi: 10.1038/s41398-018-0164-0.

41. Leaver AM, Espinoza R, Joshi SH, Vasavada M, Njau S, Woods RP, et al. Desynchronization and Plasticity of striatofrontal connectivity in major depressive disorder. Cereb Cortex. 2016;26(11):4337-46. doi: 10.1093/cercor/bhv207.

42. Oldehinkel M, Beckmann CF, Pruim RH, van Oort ES, Franke B, Hartman CA, et al. Attention-Deficit/Hyperactivity Disorder symptoms coincide with altered striatal connectivity. Biol Psychiatry Cogn Neurosci Neuroimaging. 2016;1(4):35363. doi: 10.1016/j.bpsc.2016.03.008.

43. Jackson AF, Bolger DJ. The neurophysiological bases of EEG and EEG measurement: a review for the rest of us. Psychophysiology. 2014;51(11):1061-71. doi: 10.1111/ psyp.12283.

44. Wang XJ. Neurophysiological and computational principles of cortical rhythms in cognition. Physiol Rev. 2010;90(3):1195268. doi: 10.1152/physrev.00035.2008.

45. Hari R, Parkkonen L. The brain timewise: how timing shapes and supports brain function. Philos Trans R Soc Lond B Biol Sci. 2015;370(1668):pii: 20140170. doi: 10.1098/ rstb.2014.0170.

46. Luck SJ. An introduction to the event-related potential technique. 2nd ed. Cambridge, Mass: The MIT Press; 2014.p.x.

47. Nelson CA, 3rd, McCleery JP. Use of event-related potentials in the study of typical and atypical development. J Am Acad Child Adolesc Psychiatry. 2008;47(11):1252-61. doi: 10.1097/CHI.0b013e318185a6d8.

48. Bentin S, Allison T, Puce A, Perez E, McCarthy G. Electrophysiological Studies of Face Perception in Humans. J Cogn Neurosci. 1996;8(6):551-65. doi: 10.1162/ jocn.1996.8.6.551.

49. Taylor MJ, Batty M, Itier RJ. The faces of development: a review of early face processing over childhood. J Cogn Neurosci. 2004;16(8):1426-42. doi: 10.1162/0898929042304732.

50. Dawson G, Webb SJ, Wijsman E, Schellenberg G, Estes A, Munson J, et al. Neurocognitive and electrophysiological evidence of altered face processing in parents of children with autism: implications for a model of abnormal development of social brain circuitry in autism. Dev Psychopathol. 2005;17(3):679-97. doi: 10.1017/S0954579405050327.

51. Kang E, Keifer CM, Levy EJ, Foss-Feig JH, McPartland JC, Lerner MD. Atypicality of the N170 event-related potential in autism spectrum disorder: A meta-analysis. Biol Psychiatry Cogn Neurosci Neuroimaging. 2018;3(8):657-66. doi: 10.1016/j.bpsc.2017.11.003.

52. Maher S, Mashhoon Y, Ekstrom T, Lukas S, Chen Y. Deficient cortical face-sensitive N170 responses and basic visual processing in schizophrenia. Schizophr Res. 2016;170(1):8794. doi: 10.1016/j.schres.2015.12.005.
53. McCleery A, Lee J, Joshi A, Wynn JK, Hellemann GS, Green MF. Meta-analysis of face processing event-related potentials in schizophrenia. Biol Psychiatry. 2015;77(2):11626.10.1016/j.biopsych.2014.04.015

54. Foss-Feig JH, Adkinson BD, Ji JL, Yang G, Srihari VH, McPartland JC, et al. Searching for cross-diagnostic convergence: neural mechanisms governing excitation and inhibition balance in schizophrenia and autism spectrum disorders. Biol Psychiatry. 2017;81(10):848-61. doi: 10.1016/j.biopsych.2017.03.005.

55. Riesel A. The erring brain: Error-related negativity as an endophenotype for OCD-A review and meta-analysis. Psychophysiology. 2019;56(4):e13348. doi: 10.1111/ psyp. 13348

56. Liotti M, Pliszka SR, Perez R, Kothmann D, Woldorff MG. Abnormal brain activity related to performance monitoring and error detection in children with ADHD. Cortex. 2005;41(3):377-88. https://doi.org/10.1016/S00109452(08)70274-0.

57. Siegel M, Donner TH, Engel AK. Spectral fingerprints of large-scale neuronal interactions. Nat Rev Neurosci. 2012;13(2):121-34. doi: 10.1038/nrn3137.

58. Cavanagh JF, Frank MJ. Frontal theta as a mechanism for cognitive control. Trends Cogn Sci. 2014;18(8):414-21. doi: 10.1016/j.tics.2014.04.012.

59. Sauseng P, Griesmayr B, Freunberger R, Klimesch W. Control mechanisms in working memory: a possible function of EEG theta oscillations. Neurosci Biobehav Rev. 2010;34(7):101522. doi: 10.1016/j.neubiorev.2009.12.006

60. Klimesch W. alpha-band oscillations, attention, and controlled access to stored information. Trends Cogn Sci. 2012;16(12):606-17. doi: 10.1016/j.tics.2012.10.007.

61. Buzsaki G, Wang XJ. Mechanisms of gamma oscillations. Annu Rev Neurosci. 2012;35:203-25. doi: 10.1146/annurevneuro-062111-150444.

62. Cohen MX. Analyzing neural time series data: theory and practice. Cambridge, Mass: The MIT Press; 2014.

63. Roach BJ, Mathalon DH. Event-related EEG time-frequency analysis: an overview of measures and an analysis of early gamma band phase locking in schizophrenia. Schizophr Bull. 2008;34(5):907-26. doi: 10.1093/schbul/sbn093.

64. Jaime M, McMahon CM, Davidson BC, Newell LC, Mundy PC, Henderson HA. Brief Report: Reduced Temporal-Central EEG Alpha Coherence During Joint Attention Perception in Adolescents with Autism Spectrum Disorder. J Autism Dev Disord. 2016;46(4):1477-89. doi: 10.1007/s10803-015-26673.

65. Shephard E, Tye C, Ashwood KL, Azadi B, Asherson P, Bolton PF, et al. Resting-State Neurophysiological Activity Patterns in Young People with ASD, ADHD, and ASD + ADHD. J Autism Dev Disord. 2018;48(1):110-22. doi: 10.1007/s10803-017-3300-4.

66. Shephard E, Tye C, Ashwood KL, Azadi B, Johnson MH, Charman $\mathrm{T}$, et al. Oscillatory neural networks underlying resting-state, attentional control and social cognition task conditions in children with ASD, ADHD and ASD+ADHD. Cortex. 2019;117:96-110. doi: 10.1016/j.cortex.2019.03.005.

Received: June 27, 2019

Accepted: July 12, 2019 